\title{
Lower Extremity Peripheral Arterial Disease
}

\author{
Aditya M. Sharma ${ }^{1}$ and Herbert D. Aronow ${ }^{2}$ \\ ${ }^{1}$ Saint Joseph Mercy Hospital, Department of Internal Medicine, Ann Arbor, MI, \\ ${ }^{2}$ Michigan Heart and Vascular Institute, Ann Arbor, MI, \\ USA
}

\section{Introduction}

Lower extremity peripheral arterial disease (PAD) is a disorder characterized by atherosclerotic narrowing or occlusion of the lower limb arteries. In addition to its association with impaired mobility and functional status, PAD is a marker of systemic atherosclerosis and is associated with a high incidence of cardiovascular events such as stroke, myocardial infarction (MI) and vascular death.

\section{Epidemiology}

Eight to 12 million people in United States have PAD (Allison et al. 2007). Only 10\% of patients with PAD have classic intermittent claudication (IC), $\sim 50 \%$ have atypical leg symptoms and $\sim 40 \%$ are asymptomatic (Hiatt 2001). Its prevalence significantly increases with age; $12-20 \%$ of those above the age of 65 years suffer from PAD (Ostchega al. 2007). The prevalence of PAD is similar in men and women; however men are more likely to have symptomatic disease (Ness et al. 2000; Aronow et al. 2002; Selvin and Erlinger 2004; Ostchega et al. 2007).

PAD is a polyvascular disease. Sixty to $90 \%$ of patients with PAD also have significant coronary artery disease (CAD) and up to $25 \%$ have significant carotid artery stenosis (Hertzer et al. 1984; Klop et al. 1991; Valentine et al. 1994; Cheng et al. 1999; McFalls et al. 2004; Steg et al. 2007). In a study at the Cleveland Clinic, all patients undergoing vascular surgery between 1978 and 1981 had coronary angiogram. Only 10\% of those patients had normal coronaries and $28 \%$ had severe 3 vessel coronary artery disease requiring surgical or catheter based intervention (Hertzer et al. 1984). Patients with PAD have a 3-fold greater 10year risk (RR, 3.1; 95\% CI, 1.9-4.9) of all-cause death and a 6-fold greater risk (RR, 6.6; 95\% CI, 2.9-14.9) of cardiovascular (CV)-related death compared to patients without PAD (Criqui et al. 1992). In the REACH registry, by one year, $21 \%$ of patients with PAD had developed MI, stroke, cardiovascular death or hospitalization compared with $15 \%$ of patients with CAD (Steg et al. 2007).

\section{Risk factors for PAD}

Risk factors for PAD are similar to those for atherosclerotic disease in other vascular beds with some variation in their individual attributable risks. 


\subsection{Cigarette smoking}

A strong predictor of prevalent PAD and its progression; it also predicts bypass graft and endovascular intervention failure. (Sapoval et al. 1996; Hirsch et al. 2001; Willigendael et al. 2005; Aboyans et al. 2006). Smoking increases the risk of lower extremity peripheral arterial disease by 2- to 6-fold and the risk of intermittent claudication by 3- to 10-fold (Kannel and McGee 1985; Smith et al. 1990; Bowlin et al. 1994; Meijer et al. 1998). 80\% of patients with PAD have a smoking history (Smith et al. 1990; Meijer et al. 1998). Interestingly, cigarette smoking is a stronger risk factor for PAD than for CAD with smoker's having a 2 to 3 times greater likelihood of developing PAD than CAD (Hirsch et al. 2001). It is also an independent predictor of the risk for unplanned urgent revascularization of the lower extremities following initial successful treatment (Shamma et al. 2003). With an increasing number of pack years, there is an increase in severity of disease, increased risk of amputation, peripheral graft occlusion and overall mortality.

\subsection{Diabetes Mellitus (DM)}

The risk of prevalent PAD doubles in the setting of impaired glucose tolerance (Beckman et al. 2002) and increases by 2 to 4 fold in patients with overt diabetes mellitus. PAD presents at an earlier age in diabetics; the prevalence of PAD is 20\% in diabetic patients older than 40 years and increases to $\sim 30 \%$ among those older than 50 years (Hirsch et al. 2001; 2003). Diabetics tend to have more severe degrees of stenosis and a higher preponderance toward calcification as compared to non-diabetic patients with PAD (Jude et al. 2001). PAD is more likely to remain asymptomatic in diabetics until very advanced. Finally, poor glvcemic control is associated with more rapid PAD progression, increased risk of amputation and mortality (Jude et al. 2001; Beckman et al. 2002).

\subsection{Hypertension and dyslipidemia}

Although the attributable risk for these factors is less than for DM or smoking, their adverse impact is clear from multiple studies. Uncontrolled higher blood pressures are associated with increased severity of PAD (Ness et al. 2000; Hirsch et al. 2001; Selvin and Erlinger 2004; Ostchega et al. 2007). Elevated total and LDL cholesterol, low HDL cholesterol and hypertriglyceridemia are associated with prevalent PAD (Kannel and Shurtleff 1973; Fowkes et al. 1992; Hiatt et al. 1995; Murabito et al. 2002). The risk of developing PAD increases by $5-10 \%$ with each $10 \mathrm{mg} / \mathrm{dl}$ increase in total cholesterol (Ingolfsson et al. 1994; Murabito et al. 1997).

\subsection{Renal insufficiency}

Patients with chronic kidney disease (creatinine clearance $<60 \mathrm{ml} / \mathrm{min}$ ) and end stage renal disease have a higher prevalence of IC and low ankle-brachial index (ABI) as compared to patients with normal renal function (O'Hare et al. 2004). They also have a higher prevalence of critical limb ischemia and increased incidence of peri and post operative mortality related to lower extremity revascularization procedures (O'Hare et al. 2003). Potential mechanisms include altered calcium-phosphorus, homocysteine, and lipoprotein (a) metabolism and altered inflammatory and coagulation pathways. 


\subsection{Inflammation}

A number of inflammatory markers are associated with prevalent PAD and outcomes among those with PAD. In a meta-analysis, the odds ratio for PAD in patients with increased homocysteine was 6.8 (Boushey et al. 1995). 30-40\% of PAD patients have elevated homocysteine levels as compared with 3-5\% of the general population (Hajjar 1993). Elevated C - reactive protein and D-dimer are associated with increased cardiovascular mortality in PAD patients (Vidula et al. 2008).

\subsection{Age}

The Prevalence of PAD increases with age. In the NHANES study, the prevalence of PAD increased significantly with each decade since beyond 40 years (Selvin and Erlinger 2004) (Table 1). In a German epidemiologic study, $21 \%$ of the patients above the age of 65 years had symptomatic or asymptomatic PAD yet again demonstrating increased incidence of PAD with age (Diehm et al. 2009).

\begin{tabular}{|cc|}
\hline Age (yrs) & Prevalence of PAD \\
\hline $40-49$ & $0.9 \%$ \\
$50-59$ & $2.5 \%$ \\
$60-69$ & $4.7 \%$ \\
$>70$ & $14.5 \%$ \\
\hline
\end{tabular}

Table 1. In the NHANES study, prevalence of PAD increased significantly with age.

\subsection{Race/ethnicity}

The prevalence of PAD varies by ethnicity and race. Non-hispanic blacks have the highest prevalence, followed by Mexican Americans and non-Hispanic whites, with 19.5\%, 15.6\% and $11.7 \%$ above the age of 60 years having PAD, respectively (Ostchega et al. 2007). It is believed that these relationships are mediated by a genetic predisposition in part secondary to variations in atherogenic and prothrombotic factors (Folsom et al. 1992; Conlan et al. 1993; Gerhard et al. 1999).

\section{Clinical presentation}

PAD can present in the following forms (Hirsch et al. 2006):

4.1 Intermittent claudication: Exertional symptoms such as muscle pain, cramping, discomfort or fatigue in the legs which resolves with rest of 10 minutes or less. However, these 'classic' symptoms are seen in only $10 \%$ of patients with PAD.

4.2 "Atypical” leg pain: Exertional leg symptoms which may not always resolve with rest or are not consistently reproducible.

4.3 Asymptomatic: $40 \%$ of patients with PAD have no leg symptoms but most will have some other form of functional limitations.

4.4 Acute limb ischemia: A potentially limb threatening syndrome, classically manifest by one of more of the following five " $\mathrm{P}^{\prime} \mathrm{s}$ " - pain, pulselessness, paralysis, paresthesias and pallor. 
4.5 Chronic limb ischemia (also known as 'critical limb ischemia [CLI]): Accounts for 1-2\% of all patients with PAD. It presents as rest pain, non-healing ulcers and/or gangrene.

The severity of symptoms usually correlates with degree of stenosis, adequacy of collateral circulation and level of exertion. Location of the discomfort may shed light on the location of stenosis (Table 2).

\begin{tabular}{ll}
\hline Lesion location & Site of symptoms \\
\hline Isolated infra-popliteal & Foot \\
Popliteal & Calf \\
Femoral & Calf \\
Iliac & Calf, thigh possibly impotence \\
Aorto-iliac & Bilateral calf, thigh, buttock, impotence \\
Deep femoral artery & Thigh \\
Internal iliac artery & Buttock and hip, impotence if bilateral disease \\
\hline
\end{tabular}

Table 2. Level of disease and associated symptoms

\section{Natural history of PAD}

Over a 5 -year period, only $1-2 \%$ of claudicants and asymptomatic patients develop CLI. Nevertheless, the overall mortality rate is $15-30 \%$ (75\% of which is cardiovascular) and risk of non-fatal MI or stroke $20 \%$ at 5 years. Patients with CLI have much worse outcomes with an annual CV mortality of $25 \%$ and annual amputation rate of $25 \%$.

It is noteworthy that the burden of PAD may not correlate with the presence or absence of claudication. Patients who are more physically active are more likely to present with claudication than those who lead a sedentary lifestyle. Patients who are too sedentary to claudicate may present with CLI as their first manifestation of disease.

\section{Classification of PAD}

The Rutherford and Fontaine classifications (Table 3) are frequently utilized to classify PAD symptom severity.

\begin{tabular}{lllll}
\hline & Fontaine classification & Rutherford system & \\
\hline Stage & Clinical & Grade & Category & Clinical \\
I & Asymptomatic & 0 & 0 & Asymptomatic \\
II a & Mild claudication & I & 1 & Mild claudication \\
II b & Moderate - severe claudication & I & 2 & Moderate claudication \\
& & I & 3 & Severe claudication \\
III & Ischemic rest pain & II & 4 & Ischemic rest pain \\
IV & Ulceration or gangrene & III & 5 & Tissue ulceration (minor) \\
& & IV & 6 & Tissue loss/gangrene \\
\hline
\end{tabular}

Table 3. Rutherford and Fontaine classification for PAD.

\section{Physical exam}

A comprehensive vascular history and physical exam is vital in the evaluation and appropriate treatment of patient with PAD or suspected PAD. Current ACC / AHA guidelines recommend a complete vascular exam (class I B) for patients with intermittent claudication (Hirsch et al. 2006). 
The key components of physical exam are:

- Bilateral arm blood pressure (to screen for subclavian stenosis/upper extremity PAD)

- Cardiac examination

- Assessment of the abdomen for aortic aneurysmal and stenotic disease

- Thorough Examination of legs and feet

- Pulse

- Carotid

- Radial/ulnar

- Femoral

- Popliteal

- $\quad$ Dorsalis pedis (DP)

- $\quad$ Posterior tibial (PT)

Pulse should be graded on a scale of $0-3$. $0=$ absent, $1=$ dampened, $2=$ normal or $3=$ bounding. If no pulse is palpable on exam, a Doppler exam using a hand-held continuous wave device should be performed. An absent or abnormal PT pulse has a very high specificity for diagnosis of PAD. An absent or abnormal DP is non-specific due to a high prevalence of absent or anomalous DP in the general population.

- It is also vital to asses for vascular bruits (carotid, abdominal, femoral, and popliteal)

- Other characteristics that may be seen in lower extremity PAD:

- Hair loss

- Nail hypertrophy

- Rapid elevation pallor or dependent rubor.

- Foot examinations should be performed at each visit for patients with PAD to assess for tissue loss (i.e., ulcers or gangrene) as well as for signs of other foot pathology such as callous formation or neuropathy.

\section{Screening for asymptomatic patients}

In the PAD Awareness, Risk and Treatment: New Resources for Survival (PARTNERS) study, 6979 patients aged $\geq 70$ years or aged 50-69 years with a history of cigarette smoking or diabetes were screened with ABI's (Hirsch et al. 2001). PAD (defined as an ABI of $\leq 0.90$ ) was diagnosed in $29 \%$ of this cohort. This diagnosis would have been missed in $85 \%$ to $90 \%$ had physicians relied solely on patients presenting with intermittent claudication (Hirsch et al. 2001). Even patients with IC infrequently report this symptom as they attribute it to the normal aging process (Dormandy and Rutherford 2000). A German epidemiologic study which included 6880 patients > 65 years of age reported that $21 \%$ of these patients had asymptomatic or symptomatic PAD (Diehm et al. 2009). Given that up to 50\% of patients with PAD may be asymptomatic, it is critical that these high risk patients are identified so that appropriate interventions may be initiated to prevent the associated morbidity and mortality. ACC / AHA guidelines recommend screening ABI's among high risk patients (class IC) defined as individuals with 1 or more of the following: exertional leg symptoms, non-healing wounds, age 65 years and older, or 50 years and older with a history of smoking or diabetes (Rooke et al. 2011).

The ADA also recommends that any diabetic patient above the age of 50 years who has a normal ABI should have ABI's repeated every 5 years (American Diabetic Association 2003). 


\section{Diagnostic evaluation}

It is necessary to differentiate claudication from other conditions causing leg pain when evaluating patients with PAD. Patients may have an abnormal ABI and present with leg pain unrelated to PAD. Claudication may be confused with pseudoclaudication resulting from spinal stenosis, nerve compression syndromes, arthritic pain or venous claudication. Certain clinical features help differentiate these conditions Questionnaires have also been frequently used for identifying, monitoring, assessing severity of PAD and treatment success. The Rose claudication questionnaire is a simple screening tool for claudication which can be administered by asking 2 simple questions; "Do you get pain in either leg when you walk?" and "Does the pain go away when you stop walking?" If the answer to both the question is yes then the like hood for PAD is 95\% (Rose 1962). There is an updated version of the World Health Organization Rose Questionnaire and also the Edinburgh Claudication Questionnaire which are used to diagnose PAD and the Walking Impairment Questionnaire, the Peripheral Artery Questionnaire and the Medical Outcomes Study 36Item Short Form Health Survey are used to assess severity of PAD and assess response to therapy (Criqui al. 1985; Leng and Fowkes 1992; Criqui et al. 1996; Spertus et al. 2004).

\section{Diagnostic tests}

Physiological studies such as the ABI, segmental limb pressures, or pulse-volume waveform analysis can help identify functional limb perfusion abnormalities. Imaging methods, such as duplex ultrasonography, CT angiography (CTA) and magnetic resonance angiography (MRA) provide detailed anatomical, but less frequently functional information on limb perfusion. Diagnostic modalities and respective clinical indications appear in Table 4.

\subsection{Ankle-Brachial Index}

ABI measurement is the universally accepted standard for the initial diagnostic evaluation of patients with suspected PAD and for high risk asymptomatic patients (Hirsch, Haskal et al. 2006; Mohler and Giri 2008; Rooke et al. 2011). It is simple, reliable, extremely sensitive (79 $95 \%)$ and specific $(96-100 \%)$ and can be performed in a primary care office in $<15$ minutes (Fowkes 1988; Lijmer et al. 1996). The ABI is calculated by measuring the systolic blood pressure in each arm (brachial artery) and ankle (dorsalis pedis and posterior tibial arteries) using a hand held Doppler device in a patient who has been resting in the supine position for 10 minutes. The right $\mathrm{ABI}=$ higher right ankle pressure/higher pressure in either arm; the left $\mathrm{ABI}=$ higher left ankle pressure/higher pressure in either arm. An ABI $\leq 0.90$ suggests PAD with $\geq 50 \%$ stenosis in at least one artery. (Fowkes 1988; Lijmer, Hunink et al. 1996).

Based on publication of the results of the Ankle Brachial Index Collaboration, a normal ABI range is defined as between 1.00 to 1.40 , and abnormal values continue to be defined as those $\leq 0.90$. ABI values of 0.91 to 0.99 are considered "borderline" and values $\geq 1.40$ indicates noncompressible arteries (Fowkes, Murray et al. 2008; Rooke, Hirsch et al. 2011).

In addition to its diagnostic utility, the $\mathrm{ABI}$ also provides important prognostic and functional information. The relative risk of mortality increases by $3.1 \%$ with a decrease of 0.50 in ABI. Sikkink et al followed 150 patients who were $>40$ years of age and had ABI< 0.90 and found that the cumulative survival at 5 years was $63 \%$ for patients with an ABI of < $0.50,71 \%$ for patients with an $\mathrm{ABI}$ of 0.50 to 0.69 , and $91 \%$ for those with an $\mathrm{ABI}$ of $\geq 0.70$ 
(Sikkink et al. 1997). McDermott and colleagues found that poor functional outcomes were associated with lower ABI's (McDermott et al. 2002). Interestingly, functional outcomes did not correlate with leg symptoms, again confirming that leg symptoms are a poor marker for identifying PAD severity.

Resting ABI may be insensitive for detecting aorto-iliac occlusive disease. ABI after exercise should be performed in these patients if PAD is suspected. If resting values in patients with intermittent claudication are normal, then ABI should be repeated after exercise. Incompressible arteries (e.g., elderly, diabetes, renal failure) may yield falsely normal or elevated ABI measurements. Toe- brachial index (TBI) measurement or pulse volume recording measurements should be performed in these patients as they are more accurate in this setting(Rooke et al. 2011).

\subsection{Segmental Pressure Examination (SPE) and Pulse Volume Recordings (PVR)}

SPE is a physiological test helpful in identifying location of individual arterial stenoses. It is performed by placing blood pressure cuffs at the upper thigh, the lower thigh, the upper calf and the lower calf above the ankle. Systolic blood pressure measurements are obtained at all these sites and both brachial arteries. A difference of $\geq 20 \mathrm{~mm} \mathrm{Hg}$ between two adjacent segments is considered physiologically significant. For example, a significant pressure gradient between left upper thigh cuff and left lower thigh cuff would indicate a physiologically significant stenosis in the left superficial femoral artery. As with the ABI, pressures may be elevated or uninterpretable in patients with non-compressible vessels. Pulse volume recordings are performed by measuring volume changes in the limb along with segmental pressure recordings (Darling et al. 1972). Segmental pressure examination when performed with pulse volume recordings has an overall accuracy of $90-95 \%$ in assessing the location and severity of arterial stenosis (Symes et al. 1984).

\subsection{Duplex ultrasound}

It is recommended by ACC / AHA guidelines (Class I) for routine surveillance after femoral-popliteal or femoral-tibial pedal bypass with a venous conduit (Hirsch et al. 2006).

The 2011 ACC/AHA guidelines recommend that segmental pressures, Doppler waveform analysis, pulse volume recordings, or ABI with duplex ultrasonography (or some combination of these methods) to document the presence and location of PAD in the lower extremity can be used (Rooke et al. 2011). In general, imaging studies are reserved for patients with PAD in whom revascularization is planned, for bypass graft or percutaneous vascular intervention surveillance or for cases in which the diagnosis of PAD or etiology of PAD is unclear such as arterial aneurysm, fibromuscular dysplasia, entrapment syndrome or vasculitis. Imaging studies are also used to diagnose PAD in patients with noncompressible vessels such as those with $\mathrm{ABI}>1.3$.

Physiological testing such as ABI and PVR are adequate for asymptomatic patients. For symptomatics (claudication or pseudoclaudication) ABI and PVR with or without exercise, duplex or dopler ultrasound are utilised. CTA, MRA or duplex / doppler ultrasound are usually used for patients considered for revascularization as well as for post endovascular interventions and follow ups as well as for post vein graft follow ups. 


\section{Management of Peripheral Arterial Disease}

Guidelines for the management of PAD have been published by

a. American college of Cardiology / American Heart Association which was a Collaborative Report from the American Association for Vascular Surgery/ Society for Vascular Surgery, Society for Cardiovascular Angiography and Interventions, Society for Vascular Medicine and Biology, Society of Interventional Radiology, and the ACC/AHA Task Force on Practice Guidelines

b. Scottish Intercollegiate Guidelines Network (SIGN), and

c. Trans-Atlantic Inter-Society Consensus (TASC) II (Dormandy and Rutherford 2000; Hirsch et al. 2006; Network 2006; Norgren et al. 2007).

Each of these guidelines focuses on management of PAD as a two-tiered process. First and foremost, they recommend cardiovascular risk reduction through vascular risk factor modification and antiplatelet therapy and second, symptom-guided therapy including supervised exercise, pharmacological interventions and revascularization procedures, when needed.

\subsection{Cardiovascular risk factor modification}

\subsubsection{Smoking cessation}

Patients with PAD should be referred to a formal smoking cessation program including pharmacotherapy when appropriate. A Cochrane review of 20 prospective cohort studies showed that smoking cessation is associated with a $36 \%$ risk reduction in cardiovascular events in patients with known atherosclerotic disease (Critchley and Capewell 2004) and is recommended by all three guidelines(Dormandy and Rutherford 2000; Hirsch et al. 2006; Network 2006; Norgren et al. 2007; Rooke et al. 2011); Smoking cessation is achieved in approximately $5 \%$ of patients with physician encouragement and advice along with regular follow-ups and as compared to $0.1 \%$ without physician intervention at 1 year (Law and Tang 1995). Success rates are higher with interventions such as nicotine replacement, bupropion or varenicline. When compared with usual care, formal smoking cessation program which consisted of a strong physician message and 12 two-hour group sessions, using behavior modification and nicotine gum had a higher success rate at 5 years $(22 \%$ vs. $5 \%$ ) (Anthonisen et al. 2005). Abstinence rates with bupropion at 3-, 6- and 12- month follow up are $34 \%, 27 \%$ and $22 \%$ respectively, compared with $15 \%, 11 \%$ and $9 \%$, for placebo(Tonstad et al. 2003). A combination of bupropion and nicotine replacement is superior to nicotine replacement alone, however but has similar in efficacy to only monotherapy with bupropion (Jorenby et al. 1999). Varenicline has been proven effective in smokers with cardiovascular disease including those with PAD. Rigotti et al conducted a multicenter, randomized, double-blind, placebo-controlled trial comparing the efficacy and safety of varenicline (12 weeks treatment) with placebo showed a continuous abstinence rate was higher for varenicline than placebo during weeks 9 through $12(47.0 \%$ versus $13.9 \%$;) and weeks 9 through 52 (19.2\% versus $7.2 \%)$. The varenicline and placebo groups did not differ significantly in cardiovascular mortality, all-cause mortality, cardiovascular events, or serious adverse events. (Rigotti et al. 2010). Another RCT compared varenicline vs. bupropion vs placebo showed varenicline was more efficacious than bupropion or placebo in short term (9-12 weeks) $(43.9 \%$ vs. $29.8 \%$ vs. 17.6$) \%$ as well as long term period 9 - 52 weeks) ( $23 \%$ vs. $14.6 \%$ vs. $10.3 \%$ ) (Jorenby et al. 2006). 


\subsubsection{Diabetes Mellitus}

Approximately 20-30\% in patients with DM have PAD (Marso and Hiatt 2006). The severity of PAD in this cohort correlates with the duration and severity of DM (Selvin et al. 2004; Wattanakit et al. 2005). With every $1 \%$ increase in glycosylated hemoglobin levels, the risk of PAD increases by $28 \%$ (Selvin et al. 2004)and risk of intermittent claudication by 3.5- and 8.6-fold in men and women, respectively (Kannel and McGee 1985). DM may also lead to peripheral neuropathy and decreased resistance to infection, which increases the risk of infected foot ulcers. Patients with DM are at a higher risk of amputation and have reduced primary patency after revascularization as compared to non-diabetics (Bild et al. 1989; DeRubertis et al. 2008). The UKPDS study showed that the overall microvascular complication rate decreased by $25 \%$ by lowering blood glucose levels in type 2 diabetes with intensive therapy, which achieved a median $\mathrm{HbA}_{1 \mathrm{c}}$ of $7.0 \%$ compared with conventional therapy with a median $\mathrm{HbA}_{1 \mathrm{c}}$ of $7.9 \%$. No significant effect on cardiovascular complications was observed. A non-significant $(p=0.052) 16 \%$ reduction in the risk of combined fatal or nonfatal myocardial infarction and sudden death was observed (UKPDS 1998).

The American Diabetic Association recommends maintaining hemoglobin A1c below 7\% to reduce microvascular events (ADA 2010). This recommendation is endorsed by all three PAD guidelines. The ADA also recommends comprehensive foot care including proper footwear, regular podiatric foot and nail care, daily foot inspection, skin cleansing, and use of topical moisturizing creams (ADA 2010).

\subsubsection{Dyslipidemia}

The Heart Protection Study (HPS) randomized 20,536 high-risk patients to $40 \mathrm{mg} / \mathrm{d}$ of simvastatin or placebo, including 6,748 patients with PAD. PAD patients taking statins had a $25 \%$ cardiovascular risk reduction at 5 years independent of baseline LDL level (HPS 2002). Statin use is also associated with reduction in the risk of new or worsening claudication (Pedersen, Kjekshus et al. 1998). A RCT comparing high dose atorvastatin (80 $\mathrm{mg}$ ) vs. placebo irrespective of baseline LDL cholesterol showed that high dose atorvastatin improves pain-free walking distance and community-based physical activity in patients with intermittent claudication, however there was no change noted in the maximal walking time. This beneficial effect was noted over statins cardiovascular risk reduction benefits. (Mohler, Hiatt et al. 2003).

The AHA / ACC and TASC 2 guidelines recommend the following for dyslipidemia management in patients with PAD (Dormandy and Rutherford 2000; Smith et al. 2001; Hirsch et al. 2006; Norgren, Hiatt et al. 2007).

- All patients should have low-density lipoprotein (LDL)- cholesterol $<2.59 \mathrm{mmol} / \mathrm{L}$ $(<100 \mathrm{mg} / \mathrm{dL})$.

- In patients with PAD and a history of vascular disease in other beds (e.g. coronary artery disease) it is reasonable to lower LDL cholesterol levels to $<1.81 \mathrm{mmol} / \mathrm{L}$ ( $<70 \mathrm{mg} / \mathrm{dL}$ ).

- In patients with elevated triglyceride levels where the LDL cannot be accurately calculated, the LDL level should be directly measured and treated to the above targets. Alternatively, the non-HDL (high-density lipoprotein) cholesterol level can be calculated with a goal of $<3.36 \mathrm{mmol} / \mathrm{L}(<130 \mathrm{mg} / \mathrm{dL})$, and in high risk patients $<2.59$ $\mathrm{mmol} / \mathrm{L}(<100 \mathrm{mg} / \mathrm{Dl})$.

- Dietary modification should be the initial intervention to control abnormal lipid levels [B]. 
- In symptomatic PAD patients, statins should be the primary agents to lower LDL cholesterol levels to reduce the risk of cardiovascular events [A].

The SIGN guidelines recommend statins for patients with PAD and total cholesterol level > $3.5 \mathrm{mmol} / 1$ (63 mg/ dl) (Network 2006).

The ACC/AHA and TASC II guidelines also recommended considering niacin / fibrates for raising HDL cholesterol and lowering triglycerides in patients with PAD who have abnormalities in these lipid fractions. Recently, the randomized trial, AIM - HIGH, failed to reduce the incidence of cardiovascular events among patients with CAD at 3 years and was terminated prematurely, raising questions about the benefit of niacin in patients with atherosclerotic vascular disease (http://www.aimhigh-heart.com/ 2011).

\subsubsection{Management of hypertension}

Blood pressure lowering by any pharmacological means reduces cardiovascular risk (Chobanian et al. 2003); however angiotensin converting enzyme inhibitors (ACEI) have benefit in patients with PAD beyond their effect on lowering blood pressure. The Heart Outcomes Prevention Evaluation (HOPE) study showed a 22\% reduction in risk of MI, stroke, or vascular death in patients randomized to ramipril compared to placebo, independent of the blood pressure-lowering effect (Yusuf et al. 2000). Although once thought to worsen claudication, the safety of beta blockers, has been demonstrated in a meta-analysis of 11 trials of patients with PAD (Radack and Deck 1991); these agents are of benefit of patients with CAD, particularly among those with a history of prior myocardial infarction.

\subsubsection{Anti-platelet therapy}

\subsubsection{Aspirin}

Aspirin was initially recommended mainly based on a sub-group analysis of a Antithrombotic Trialists' Collaboration meta-analysis which is a meta-analysis of 42 RCT's published in 2002 which showed that anti-platelet therapy (primarily aspirin) reduced cardiovascular events by $23 \%$ in patients with symptomatic PAD including patients with IC $(23 \%)$, those with peripheral grafts $(22 \%)$ and those undergoing peripheral angioplasty $(29 \%)$ (2002). However, this study had a lot of heterogeneity in selection criteria and different antiplatelet drugs used at different doses. Also the benefit of aspirin in asymptomatic PAD wasn't in this meta-analysis. A more recent meta-analysis of 18 RCT's including 5,269 patients with PAD, aspirin therapy alone or in combination with dipyridamole led to a non-significant $12 \%$ reduction in the primary end point of cardiovascular events(Berger et al. 2009). Two large RCT evaluated the benefit of aspirin in patients with asymptomatic PAD and found no benefit (Belch et al. 2008; Fowkes et al. 2010). However, both of these RCT's had populations with asymptomatic PAD with very mild decrease in ABI and characterized as mild PAD in general. In the Prevention of Progression of Arterial Disease and Diabetes (POPADAD) trial enrolled patients with ABI $<0.99$ and the Aspirin for Asymptomatic Atherosclerosis trial enrolled patient with ABI $\leq 0.95$ which calculated by using the lower pedal pressure at the ankle. In standard clinical practice and guidelines, ABI is calculated using the higher pedal pressure (Belch et al. 2008; Fowkes et al. 2010). Hence, both of these studies had significant limitations in design and enrollment and no change in recommendation regarding anti-platelet therapy in this cohort have occurred (Belch et al. 2008; Fowkes et al. 2010). 


\subsubsection{Clopidogrel}

In a post hoc subgroup analysis of 6,452 PAD patients in The Clopidogrel versus Aspirin in Patients at Risk of Ischemic Events (CAPRIE) trial, the incidence of stroke, MI, or vascular death was reduced by $24 \%$ among those randomized to clopidogrel compared to aspirin monotherapy (1996).

Dual antiplatelets therapy (DAPT) with aspirin and clopidogrel was not more effective than aspirin monotherapy in the Clopidogrel for High Atherothrombotic Risk and Ischemia Stabilization, Management and Avoidance (CHARISMA) study (Bhatt et al. 2006). However, post hoc analysis of the CHARISMA study revealed that DAPT was superior to aspirin monotherapy among patients with known symptomatic PAD at the time of enrollment (Bhatt et al. 2007). The combination of antiplatelet and anticoagulant therapy was evaluated in The Warfarin Anti-platelet Vascular Evaluation (WAVE) trial. This study found no incremental benefit of vitamin $\mathrm{K}$ antagonists when added to anti-platelet therapy for the prevention of cardiovascular events in patients with PAD (Anand et al. 2007). In fact, patients randomized to the combination of antiplatelet and anticoagulant therapy had an increase in life-threatening bleeding when compared with those randomized to anti-platelet therapy alone.

In general, all three PAD guidelines recommend antiplatelet therapy for PAD patients. Selection of an antiplatelet regimen (aspirin or clopidogrel or both or other antiplatelet medications) for the PAD patient should be individualized on the basis of tolerance and other clinical characteristics (i.e., bleeding risk) along with cost and guidance from regulatory agencies. (Dormandy and Rutherford 2000; Hirsch et al. 2006; Network 2006; Rooke et al. 2011). ACC / AHA guidelines strongly recommend antiplatelet therapy to reduce the risk of MI, stroke, and vascular death in individuals with symptomatic atherosclerotic lower extremity PAD, including those with intermittent claudication or critical limb ischemia, prior lower extremity revascularization (endovascular or surgical), or prior amputation for lower extremity ischemia (class IA). They feel that antiplatelet therapy can be useful to reduce the risk of MI, stroke, or vascular death in asymptomatic individuals with an ABI less than or equal to 0.90 (Class IIa C), however do not strongly recommend it given lack of definite evidence of any benefit (Rooke et al. 2011).

\subsection{Medical therapy for claudication}

\subsubsection{Supervised exercise program}

Many patients with PAD have severely impaired functional capacity, which leads to decreased quality of life (McDermott et al. 2004). A meta-analysis of 21 studies showed that patients with IC who underwent exercise training improved mean walking time by $180 \%$ and maximal walking time by $120 \%$ (Gardner and Poehlman 1995). Supervised treadmill exercises programs are also are more effective than lower extremity resistance training (McDermott et al. 2009). However, due to lack of reimbursement access to this important therapeutic intervention has been limited. In a Cochrane review of 8 RCT's evaluating supervised and unsupervised exercise among 319 participants with IC, statistically significant and clinically relevant improvements in maximal treadmill 
walking distance occurred with supervised compared with non-supervised exercise therapy during 12 weeks to 12 months of follow up (Bendermacher et al. 2006). Unsupervised therapy may be less effective than supervised therapy due to lack of motivation, compliance with recommended exercise, lack of progression of workload in the absence of professional supervision and concern for personal safety to advance the moderate claudication discomfort severity.

\subsubsection{Pharmacological agents}

Cilastozol is an FDA-approved medication for the management of IC. It is a reversible phosphodiesterase inhibitor whose exact mechanism of benefit is unclear. It inhibits platelet aggregation, thrombin formation, and vascular smooth muscle proliferation and acts as a vasodilator. It also increases HDL and lowers TG levels. In an analysis of 9 RCT's of cilastazol at dose of $100 \mathrm{mg}$ BID, cilostazol showed a 50.7\% improvement from baseline maximal walking distance compared to placebo (24.3\%) (Pande et al. 2010). A Cochrane review found similar benefit (Robless et al. 2008). Given the increased incidence of sudden cardiac death with other phosphodiesterase inhibitors (e.g., milrinone), cilostazol is contraindicated in patients with heart failure and/ or ejection fraction less than $40 \%$ (Packer et al. 1991). The ACC/AHA guidelines have given cilostazol a grade IA recommendation for patients with intermittent claudication in the absence of heart failure.

Pentoxifylline is a methylxanthine derivative that decreases blood viscosity and has hemorheologic (improves erythrocyte and leukocyte deformability), anti-inflammatory, and antiproliferative effects. Its anti-claudication effect has been inconsistent. A study randomizing 698 patients with IC to cilostazol, pentoxifylline or placebo did not observe any difference between pentoxifylline and placebo (Dawson et al. 2000). ACC/AHA guidelines recommend using pentoxifylline as an alternative in patients who cannot tolerate cilostazol or in whom cilostazol is contraindicated.

\subsubsection{Revascularization}

Revascularization is only appropriate for symptomatic patients and should not be undertaken as prophylactic therapy for an asymptomatic limb (Hirsch et al. 2006). Revascularization is indicated in patients' with acute limb ischemia (ALI), CLI and among those with lifestyle- or vocation-limiting claudication who have failed a trial of medical therapy or who have highly favorable anatomy for endovascular therapy such as focal aorto-iliac disease (Hirsch et al. 2006) . Data comparing medical therapy with either endovascular or surgical therapy are scant. The ongoing Claudication: exercise vs endoluminal revascularization (CLEVER) trial is comparing medical therapy alone vs. medical therapy + supervised exercise vs. medical therapy + endovascular therapy (Murphy et al. 2008).

Endovascular therapy is currently the preferred mode of revascularization in cases where anatomy is more favorable (e.g., aorto-iliac disease). Endovascular therapy is less invasive, is associated with fewer complications and with shorter hospital stay as compared to bypass procedures. The durability of endovascular or surgical procedures depends on a number of factors including anatomic location (aorto-iliac revascularization whether open surgical or endovascular has superior long term outcomes compared with infra-inguinal 
revascularization), lesion characteristics, technical features (e.g., angioplasty alone vs. angioplasty + stent, type of surgical conduit used for surgical bypass). Hybrid procedures are performed for multi-level in an effort to minimize the overall operative risk of the revascularization (e.g., iliac artery stenting followed by femoral-popliteal bypass). Open surgical revascularization (e.g., bypass or endarterectomy) is typically reserved for endovascular failures or anatomy not likely to respond to an endovascular attempt.

\section{Summary of the guideline recommendations for PAD}

In table 4 we outline the grade A level of recommendation for PAD by TASC II guidelines. In table 5 we outline the class I recommendations by American College of Cardiology and American Heart association for PAD. Finally in table 6 we outline the differences in recommendations between the TASC II and American College of Cardiology / American Heart association guidelines for management of PAD.

\begin{tabular}{|c|}
\hline TASC II grade A level of recommendation for peripheral arterial disease \\
\hline $\begin{array}{l}\text { All patients who smoke should receive a program of physician advice, group counseling sessions and } \\
\text { nicotine replacement }\end{array}$ \\
\hline $\begin{array}{l}\text { Cessation rates can be enhanced by the addition of antidepressant drug therapy (bupropion) and nicotine } \\
\text { replacement }\end{array}$ \\
\hline All symptomatic PAD patients should have their LDL-cholesterol lowered to $<2.59 \mathrm{mmol} / \mathrm{L}(<100 \mathrm{mg} / \mathrm{dL})$ \\
\hline $\begin{array}{l}\text { In symptomatic PAD patients, statins should be the primary agents to lower LDL cholesterol levels to } \\
\text { reduce the risk of cardiovascular events }\end{array}$ \\
\hline $\begin{array}{l}\text { All patients with hypertension should have blood pressure controlled to }<140 / 90 \mathrm{~mm} \mathrm{Hg} \text { or }<130 / 80 \mathrm{~mm} \\
\mathrm{Hg} \text { if they also have diabetes or renal insufficiency }\end{array}$ \\
\hline $\begin{array}{l}\text { The Joint National Committee (JNC VII) and European guidelines for the management of hypertension in } \\
\text { PAD should be followed }\end{array}$ \\
\hline Beta-adrenergic blocking drugs are not contraindicated in PAD \\
\hline $\begin{array}{l}\text { All symptomatic patients with or without a history of other cardiovascular disease should be prescribed an } \\
\text { antiplatelet drug long-term to reduce the risk of cardiovascular morbidity and mortality }\end{array}$ \\
\hline $\begin{array}{l}\text { Aspirin/ASA is effective in patients with PAD who also have clinical evidence of other forms of } \\
\text { cardiovascular disease (coronary or carotid) }\end{array}$ \\
\hline Routine coronary revascularization in preparation for vascular surgery is not recommended \\
\hline $\begin{array}{l}\text { When there are no contraindications, beta-adrenergic blockers should be given perioperatively to patients } \\
\text { with peripheral artery disease undergoing vascular surgery in order to decrease cardiac morbidity and } \\
\text { mortality }\end{array}$ \\
\hline $\begin{array}{l}\text { Supervised exercise should be made available as part of the initial treatment for all patients with peripheral } \\
\text { artery disease }\end{array}$ \\
\hline $\begin{array}{l}\text { The most effective programs employ treadmill or track walking that is of sufficient intensity to bring on } \\
\text { claudication, followed by rest, over the course of a 30-60 minute session. Exercise sessions are typically } \\
\text { conducted three times a week for } 3 \text { months }\end{array}$ \\
\hline $\begin{array}{l}\text { A 3- to 6-month course of cilostazol should be first-line pharmacotherapy for the relief of claudication } \\
\text { symptoms, as evidence shows both an improvement in treadmill exercise performance and in quality of life }\end{array}$ \\
\hline $\begin{array}{l}\text { Naftidrofuryl (Not available in United States of America) can also be considered for treatment of } \\
\text { claudication symptoms }\end{array}$ \\
\hline CLI patients should have aggressive modification of their cardiovascular risk factors \\
\hline $\begin{array}{l}\text { Antiplatelet therapy should be started preoperatively and continued as adjuvant pharmacotherapy after an } \\
\text { endovascular or surgical procedure. Unless subsequently contraindicated, this should be continued } \\
\text { indefinitely }\end{array}$ \\
\hline
\end{tabular}

Table 4. This table outlines TASC II grade A level of recommendation for peripheral arterial disease 


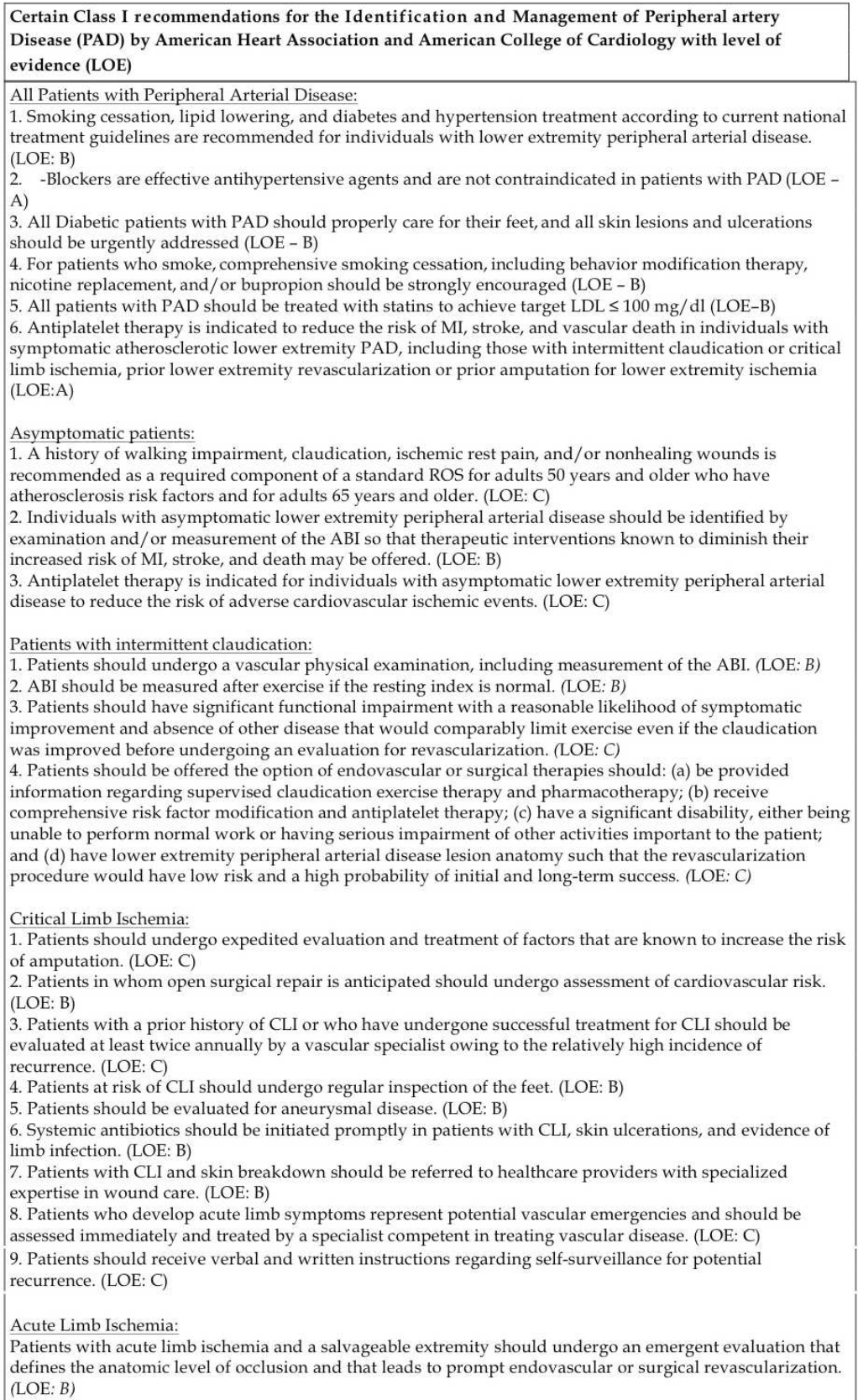

Table 5. This table outlines Class I recommendations for the Identification and Management of Peripheral artery Disease (PAD) by American Heart Association and American College of Cardiology with level of evidence (LOE) 


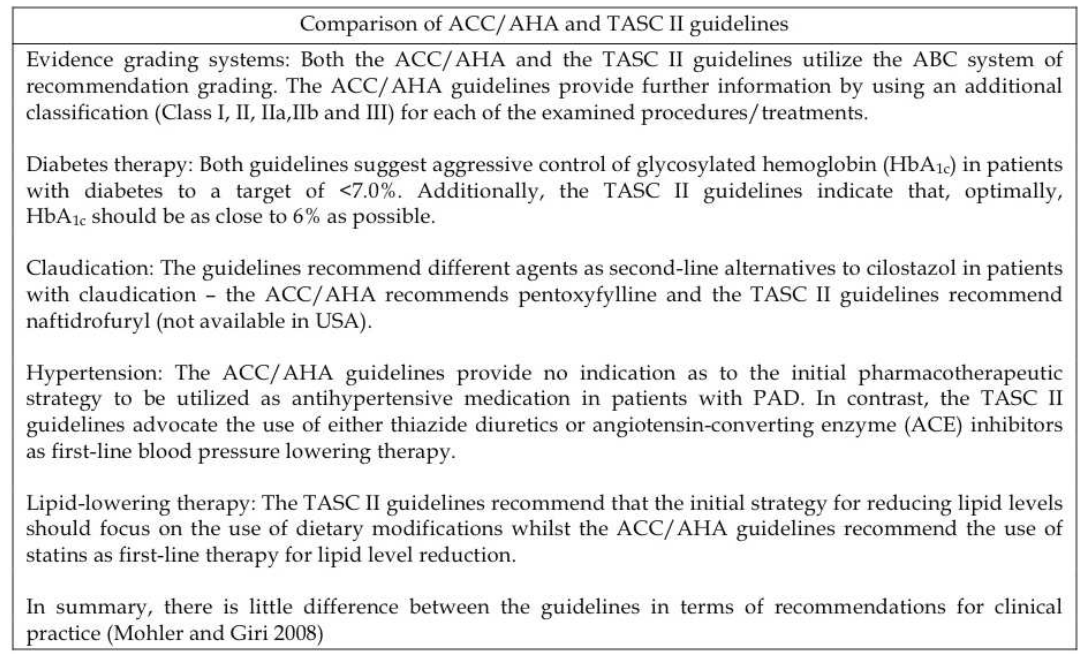

Table 6. This table outlines the main differences between the ACC/AHA PAD guidelines and TASC II guidelines are summarized in this table

\section{Conclusions}

PAD is a common disease, present in more than 8 million Americans and is associated with a relatively high risk of cardiovascular events. Nevertheless, it remains under-recognized by healthcare providers and patients alike. Increased awareness, earlier identification of the disease and aggressive medical therapy and vascular risk factor modification would reduce the likelihood of fatal and non-fatal cardiovascular events and improve overall functional status and quality of life.

\section{References}

(1996). "A randomised, blinded, trial of clopidogrel versus aspirin in patients at risk of ischaemic events (CAPRIE). CAPRIE Steering Committee." Lancet 348(9038): 13291339.

(2002). "Collaborative meta-analysis of randomised trials of antiplatelet therapy for prevention of death, myocardial infarction, and stroke in high risk patients." BMJ 324(7329): 71-86.

(2003). "Peripheral arterial disease in people with diabetes." Diabetes care 26(12): 33333341.

Aboyans, V., M. H. Criqui, et al. (2006). "Risk factors for progression of peripheral arterial disease in large and small vessels." Circulation 113(22): 2623-2629.

ADA (2010). "Standards of medical care in diabetes--2010." Diabetes care 33 Suppl 1: S1161.

Allison, M. A. et al. (2007). "Ethnic-specific prevalence of peripheral arterial disease in the United States." American journal of preventive medicine 32(4): 328-333. 
Anand, S. et al. (2007). "Oral anticoagulant and antiplatelet therapy and peripheral arterial disease." The New England journal of medicine 357(3): 217-227.

Anthonisen, N. R. et al. (2005). "The effects of a smoking cessation intervention on 14.5year mortality: a randomized clinical trial." Annals of internal medicine 142(4): 233239.

Aronow, W. S. et al. (2002). "Prevalence and incidence of cardiovascular disease in 1160 older men and 2464 older women in a long-term health care facility." The journals of gerontology. Series A, Biological sciences and medical sciences 57(1): M45-46.

Beckman, J. A et al. (2002). "Diabetes and atherosclerosis: epidemiology, pathophysiology, and management." JAMA 287(19): 2570-2581.

Belch, J. et al. (2008). "The prevention of progression of arterial disease and diabetes (POPADAD) trial: factorial randomised placebo controlled trial of aspirin and antioxidants in patients with diabetes and asymptomatic peripheral arterial disease." BMJ 337: a1840.

Bendermacher, B. L. et al. (2006). "Supervised exercise therapy versus non-supervised exercise therapy for intermittent claudication." Cochrane database of systematic reviews(2): CD005263.

Berger, J. S. et al. (2009). "Aspirin for the prevention of cardiovascular events in patients with peripheral artery disease: a meta-analysis of randomized trials." JAMA 301(18): 1909-1919.

Bhatt, D. L. et al. (2007). "Patients with prior myocardial infarction, stroke, or symptomatic peripheral arterial disease in the CHARISMA trial." Journal of the American College of Cardiology 49(19): 1982-1988.

Bhatt, D. L. et al. (2006). "Clopidogrel and aspirin versus aspirin alone for the prevention of atherothrombotic events." The New England journal of medicine 354(16): 17061717.

Bild, D. E. et al. (1989). "Lower-extremity amputation in people with diabetes. Epidemiology and prevention." Diabetes care 12(1): 24-31.

Boushey, C. J. et al. (1995). "A quantitative assessment of plasma homocysteine as a risk factor for vascular disease. Probable benefits of increasing folic acid intakes." JAMA 274(13): 1049-1057.

Bowlin, S. J. et al. (1994). "Epidemiology of intermittent claudication in middle-aged men." Am J Epidemiol 140(5): 418-430.

Cheng, S. W. et al. (1999). "Screening for asymptomatic carotid stenosis in patients with peripheral vascular disease: a prospective study and risk factor analysis." Cardiovasc Surg 7(3): 303-309.

Chobanian, A. V. et al. (2003). "The Seventh Report of the Joint National Committee on Prevention, Detection, Evaluation, and Treatment of High Blood Pressure: the JNC 7 report." JAMA 289(19): 2560-2572.

Conlan, M. G. et al. (1993). "Associations of factor VIII and von Willebrand factor with age, race, sex, and risk factors for atherosclerosis. The Atherosclerosis Risk in Communities (ARIC) Study." Thrombosis and haemostasis 70(3): 380-385. 
Criqui, M. H. et al. (1996). "The correlation between symptoms and non-invasive test results in patients referred for peripheral arterial disease testing." Vascular medicine 1(1): 65-71.

Criqui, M. H., et al. (1985). "The prevalence of peripheral arterial disease in a defined population." Circulation 71(3): 510-515.

Criqui, M. H. et al. (1992). "Mortality over a period of 10 years in patients with peripheral arterial disease." The New England journal of medicine 326(6): 381-386.

Critchley, J. and S. Capewell (2004). "Smoking cessation for the secondary prevention of coronary heart disease." Cochrane database of systematic reviews(1): CD003041.

Darling, R. C. et al. (1972). "Quantitative segmental pulse volume recorder: a clinical tool." Surgery 72(6): 873-877.

Dawson, D. L. et al. (2000). "A comparison of cilostazol and pentoxifylline for treating intermittent claudication." The American journal of medicine 109(7): 523530.

DeRubertis, B. G. et al. (2008). "Reduced primary patency rate in diabetic patients after percutaneous intervention results from more frequent presentation with limbthreatening ischemia." Journal of vascular surgery 47(1): 101-108.

Diehm, C. et al. (2009). "Mortality and vascular morbidity in older adults with asymptomatic versus symptomatic peripheral artery disease." Circulation 120(21): 20532061.

Dormandy, J. A. and R. B. Rutherford (2000). "Management of peripheral arterial disease (PAD). TASC Working Group. TransAtlantic Inter-Society Consensus (TASC)." Journal of vascular surgery 31(1 Pt 2): S1-S296.

Folsom, A. R. et al. (1992). "Distributions of hemostatic variables in blacks and whites: population reference values from the Atherosclerosis Risk in Communities (ARIC) Study." Ethnicity $\mathcal{E}$ disease 2(1): 35-46.

Fowkes, F. G. (1988). "The measurement of atherosclerotic peripheral arterial disease in epidemiological surveys." International journal of epidemiology 17(2): 248254.

Fowkes, F. et al. (1992). "Smoking, lipids, glucose intolerance, and blood pressure as risk factors for peripheral atherosclerosis compared with ischemic heart disease in the Edinburgh Artery Study." American journal of epidemiology 135(4): 331340.

Fowkes, F. G. et al. (2008). "Ankle brachial index combined with Framingham Risk Score to predict cardiovascular events and mortality: a meta-analysis." JAMA 300(2): 197-208.

Fowkes, F. G. et al. (2010). "Aspirin for prevention of cardiovascular events in a general population screened for a low ankle brachial index: a randomized controlled trial." JAMA 303(9): 841-848.

Gardner, A. W. and E. T. Poehlman (1995). "Exercise rehabilitation programs for the treatment of claudication pain. A meta-analysis." JAMA 274(12): 975-980.

Gerhard, G. T. et al. (1999). "Higher total homocysteine concentrations and lower folate concentrations in premenopausal black women than in premenopausal 
white women." The American journal of clinical nutrition 70(2): 252260.

Hajjar, K. A. (1993). "Homocysteine-induced modulation of tissue plasminogen activator binding to its endothelial cell membrane receptor." J Clin Invest 91(6): 28732879.

Hertzer, N. R. et al. (1984). "Coronary artery disease in peripheral vascular patients. A classification of 1000 coronary angiograms and results of surgical management." Annals of surgery 199(2): 223-233.

Hiatt, W. R. (2001). "Medical treatment of peripheral arterial disease and claudication." The New England journal of medicine 344(21): 1608-1621.

Hiatt, W. R. et al. (1995). "Effect of diagnostic criteria on the prevalence of peripheral arterial disease. The San Luis Valley Diabetes Study." Circulation 91(5): 14721479.

Hirsch, A. T. et al. (2001). "Peripheral arterial disease detection, awareness, and treatment in primary care." JAMA 286(11): 1317-1324.

Hirsch, A. T., Z. J. Haskal, et al. (2006). "ACC/AHA 2005 Practice Guidelines for the management of patients with peripheral arterial disease (lower extremity, renal, mesenteric, and abdominal aortic): a collaborative report from the American Association for Vascular Surgery/Society for Vascular Surgery, Society for Cardiovascular Angiography and Interventions, Society for Vascular Medicine and Biology, Society of Interventional Radiology, and the ACC/AHA Task Force on Practice Guidelines (Writing Committee to Develop Guidelines for the Management of Patients With Peripheral Arterial Disease): endorsed by the American Association of Cardiovascular and Pulmonary Rehabilitation; National Heart, Lung, and Blood Institute; Society for Vascular Nursing; TransAtlantic Inter-Society Consensus; and Vascular Disease Foundation." Circulation 113(11): e463-654.

HPS (2002). "MRC/BHF Heart Protection Study of cholesterol lowering with simvastatin in 20,536 high-risk individuals: a randomised placebo-controlled trial." Lancet 360(9326): 7-22.

http://www.aimhigh-heart.com/. (2011).

Ingolfsson, I. O. et al. (1994). "A marked decline in the prevalence and incidence of intermittent claudication in Icelandic men 1968-1986: a strong relationship to smoking and serum cholesterol--the Reykjavik Study." Journal of clinical epidemiology 47(11): $1237-1243$.

Jorenby, D. E. et al. (2006). "Efficacy of varenicline, an alpha4beta2 nicotinic acetylcholine receptor partial agonist, vs placebo or sustained-release bupropion for smoking cessation: a randomized controlled trial." JAMA 296(1): 56-63.

Jorenby, D. E. et al. (1999). "A controlled trial of sustained-release bupropion, a nicotine patch, or both for smoking cessation." The New England journal of medicine 340(9): 685-691.

Jude, E. B. et al. (2001). "Peripheral arterial disease in diabetic and nondiabetic patients: a comparison of severity and outcome." Diabetes care 24(8): 1433-1437. 
Kannel, W. B. and D. L. McGee (1985). "Update on some epidemiologic features of intermittent claudication: the Framingham Study." Journal of the American Geriatrics Society 33(1): 13-18.

Kannel, W. B. and D. Shurtleff (1973). "The Framingham Study. Cigarettes and the development of intermittent claudication." Geriatrics 28(2): 61-68.

Klop, R. B. et al. (1991). "Screening of the internal carotid arteries in patients with peripheral vascular disease by colour-flow duplex scanning." European journal of vascular surgery 5(1): 41-45.

Law, M. and J. L. Tang (1995). "An analysis of the effectiveness of interventions intended to help people stop smoking." Archives of internal medicine 155(18): 19331941.

Leng, G. C. and F. G. Fowkes (1992). "The Edinburgh Claudication Questionnaire: an improved version of the WHO/Rose Questionnaire for use in epidemiological surveys." Journal of clinical epidemiology 45(10): 1101-1109.

Lijmer, J. G. et al. (1996). "ROC analysis of noninvasive tests for peripheral arterial disease." Ultrasound in medicine $\mathcal{E}$ biology 22(4): 391-398.

Marso, S. P. and W. R. Hiatt (2006). "Peripheral arterial disease in patients with diabetes." Journal of the American College of Cardiology 47(5): 921-929.

McDermott, M. et al. (2009). "Treadmill exercise and resistance training in patients with peripheral arterial disease with and without intermittent claudication: a randomized controlled trial." JAMA 301(2): 165-174.

McDermott, M. M. et al. (2002). "The ankle brachial index is associated with leg function and physical activity: the Walking and Leg Circulation Study." Annals of internal medicine 136(12): 873-883.

McDermott, M. M. et al. (2004). "Functional decline in peripheral arterial disease: associations with the ankle brachial index and leg symptoms." JAMA 292(4): 453-461.

McFalls, E. O. et al. (2004). "Coronary-artery revascularization before elective major vascular surgery." The New England journal of medicine 351(27): 2795-2804.

Meijer, W. T. et al. (1998). "Peripheral arterial disease in the elderly: The Rotterdam Study." Arterioscler Thromb Vasc Biol 18(2): 185-192.

Mohler, E., 3rd and J. Giri (2008). "Management of peripheral arterial disease patients: comparing the ACC/AHA and TASC-II guidelines." Current medical research and opinion 24(9): 2509-2522.

Mohler, E. R., 3rd, W. R. Hiatt, et al. (2003). "Cholesterol reduction with atorvastatin improves walking distance in patients with peripheral arterial disease." Circulation 108(12): 1481-1486.

Murabito, J. M. et al. (1997). "Intermittent claudication. A risk profile from The Framingham Heart Study." Circulation 96(1): 44-49.

Murabito, J. M et al. (2002). "Prevalence and clinical correlates of peripheral arterial disease in the Framingham Offspring Study." American heart journal 143(6): 961965.

Murphy, T. P. et al. (2008). "The Claudication: Exercise Vs. Endoluminal Revascularization (CLEVER) study: rationale and methods." Journal of vascular surgery 47(6): 13561363. 
Ness, J. et al. (2000). "Risk factors for symptomatic peripheral arterial disease in older persons in an academic hospital-based geriatrics practice." Journal of the American Geriatrics Society 48(3): 312-314.

Network, S. I. G. (2006). "Diagnosis and management of peripheral arterial disease: a national clinical guideline." Edinburgh, Scotland: SIGN.

Norgren, L. et al. (2007). "Inter-Society Consensus for the Management of Peripheral Arterial Disease (TASC II)." Journal of vascular surgery 45 Suppl S: S5-67.

O'Hare, A. M. et al. (2003). "Impact of renal insufficiency on short-term morbidity and mortality after lower extremity revascularization: data from the Department of Veterans Affairs' National Surgical Quality Improvement Program." Journal of the American Society of Nephrology : JASN 14(5): 1287-1295.

O'Hare, A. M. et al. (2004). "High prevalence of peripheral arterial disease in persons with renal insufficiency: results from the National Health and Nutrition Examination Survey 1999-2000." Circulation 109(3): 320-323.

Ostchega, Y., et al. (2007). "Prevalence of peripheral arterial disease and risk factors in persons aged 60 and older: data from the National Health and Nutrition Examination Survey 1999-2004." Journal of the American Geriatrics Society 55(4): 583-589.

Packer, M. et al. (1991). "Effect of oral milrinone on mortality in severe chronic heart failure. The PROMISE Study Research Group." The New England journal of medicine 325(21): 1468-1475.

Pande, R. L et al. (2010). "A pooled analysis of the durability and predictors of treatment response of cilostazol in patients with intermittent claudication." Vascular medicine 15(3): 181-188.

Pedersen et al. (1998). "Effect of simvastatin on ischemic signs and symptoms in the Scandinavian simvastatin survival study (4S)." The American journal of cardiology 81(3): 333-335.

Radack, K. and C. Deck (1991). "Beta-adrenergic blocker therapy does not worsen intermittent claudication in subjects with peripheral arterial disease. A meta-analysis of randomized controlled trials." Archives of internal medicine 151(9): 1769-1776.

Rigotti, N. A. et al. (2010). "Efficacy and safety of varenicline for smoking cessation in patients with cardiovascular disease: a randomized trial." Circulation 121(2): 221-229.

Robless, P. et al. (2008). "Cilostazol for peripheral arterial disease." Cochrane database of systematic reviews(1): CD003748.

Rooke, T. W. et al. (2011). "2011 ACCF/AHA Focused Update of the Guideline for the Management of Patients With Peripheral Artery Disease (Updating the 2005 Guideline): A Report of the American College of Cardiology Foundation/American Heart Association Task Force on Practice Guidelines." Circulation.

Rose, G. A. (1962). "The diagnosis of ischaemic heart pain and intermittent claudication in field surveys." Bull World Health Organ 27: 645-658.

Sapoval, M. R. et al. (1996). "Self-expandable stents for the treatment of iliac artery obstructive lesions: long-term success and prognostic factors." AJR Am J Roentgenol 166(5): 1173-1179. 
Selvin, E. and T. P. Erlinger (2004). "Prevalence of and risk factors for peripheral arterial disease in the United States: results from the National Health and Nutrition Examination Survey, 1999-2000." Circulation 110(6): 738-743.

Selvin, E. et al. (2004). "Meta-analysis: glycosylated hemoglobin and cardiovascular disease in diabetes mellitus." Annals of internal medicine 141(6): 421-431.

Shammas, N. W. et al. (2003). "In-hospital complications of peripheral vascular interventions using unfractionated heparin as the primary anticoagulant." The Journal of invasive cardiology 15(5): 242-246.

Sikkink, C. J. et al. (1997). "Decreased ankle/brachial indices in relation to morbidity and mortality in patients with peripheral arterial disease." Vascular medicine 2(3): 169173.

Smith, G. D. et al. (1990). "Intermittent claudication, heart disease risk factors, and mortality. The Whitehall Study." Circulation 82(6): 1925-1931.

Smith, S. C., et al. (2001). "AHA/ACC Scientific Statement: AHA/ACC guidelines for preventing heart attack and death in patients with atherosclerotic cardiovascular disease: 2001 update: A statement for healthcare professionals from the American Heart Association and the American College of Cardiology." Circulation 104(13): 1577-1579.

Spertus, J., et al. (2004). "The peripheral artery questionnaire: a new disease-specific health status measure for patients with peripheral arterial disease." American heart journal 147(2): 301-308.

Steg, P. G. et al. (2007). "One-year cardiovascular event rates in outpatients with atherothrombosis." JAMA 297(11): 1197-1206.

Symes, J. F. et al. (1984). "Doppler waveform analysis versus segmental pressure and pulsevolume recording: assessment of occlusive disease in the lower extremity." Canadian journal of surgery. Journal canadien de chirurgie 27(4): 345-347.

Tonstad, S. et al. (2003). "Bupropion SR for smoking cessation in smokers with cardiovascular disease: a multicentre, randomised study." European heart journal 24(10): 946-955.

UKPDS (1998). "Intensive blood-glucose control with sulphonylureas or insulin compared with conventional treatment and risk of complications in patients with type 2 diabetes (UKPDS 33). UK Prospective Diabetes Study (UKPDS) Group." Lancet 352(9131): 837-853.

Valentine, R. J. et al. (1994). "Coronary artery disease is highly prevalent among patients with premature peripheral vascular disease." Journal of vascular surgery 19(4): 668674.

Vidula, H. et al. (2008). "Biomarkers of inflammation and thrombosis as predictors of nearterm mortality in patients with peripheral arterial disease: a cohort study." Annals of internal medicine 148(2): 85-93.

Wattanakit, K. et al. (2005). "Risk factors for peripheral arterial disease incidence in persons with diabetes: the Atherosclerosis Risk in Communities (ARIC) Study." Atherosclerosis 180(2): 389-397.

Willigendael, E. M. et al. (2005). "Smoking and the patency of lower extremity bypass grafts: a meta-analysis." Journal of vascular surgery 42(1): 67-74. 
Yusuf, S., P. Sleight, et al. (2000). "Effects of an angiotensin-converting-enzyme inhibitor, ramipril, on cardiovascular events in high-risk patients. The Heart Outcomes Prevention Evaluation Study Investigators." The New England journal of medicine 342(3): 145-153. 


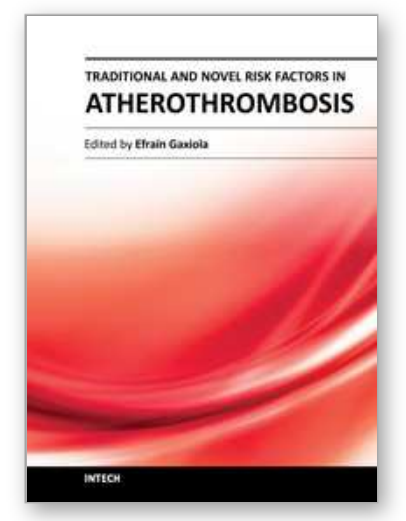

\author{
Traditional and Novel Risk Factors in Atherothrombosis \\ Edited by Dr. Efrain Gaxiola
}

ISBN 978-953-51-0561-9

Hard cover, 140 pages

Publisher InTech

Published online 20, April, 2012

Published in print edition April, 2012

Atherothrombosis has reached pandemic proportions worldwide. It is the underlying condition that results in events leading to myocardial infarction, ischemic stroke and vascular death. As such, it is the leading cause of death worldwide manifested mainly as cardiovascular/cerebrovascular death. The complex and intimate relationship between atherothrombosis and traditional and novel risk factors is discussed in the following chapters of Traditional and Novel Risk Factors in Atherothrombosis - from basic science to clinical and therapeutic concerns. Beginning with pathology and pathophysiology of atherothrombosis, plaque rupture/disruption, this book continues with molecular, biochemical, inflammatory, cellular aspects and finally analyzes several aspects of clinical pharmacology.

\title{
How to reference
}

In order to correctly reference this scholarly work, feel free to copy and paste the following:

Aditya M. Sharma and Herbert D. Aronow (2012). Lower Extremity Peripheral Arterial Disease, Traditional and Novel Risk Factors in Atherothrombosis, Dr. Efrain Gaxiola (Ed.), ISBN: 978-953-51-0561-9, InTech, Available from: http://www.intechopen.com/books/traditional-and-novel-risk-factors-in-atherothrombosis/lower-extremityperipheral-arterial-disease

\section{INTECH}

open science | open minds

\section{InTech Europe}

University Campus STeP Ri

Slavka Krautzeka 83/A

51000 Rijeka, Croatia

Phone: +385 (51) 770447

Fax: +385 (51) 686166

www.intechopen.com

\section{InTech China}

Unit 405, Office Block, Hotel Equatorial Shanghai

No.65, Yan An Road (West), Shanghai, 200040, China

中国上海市延安西路65号上海国际贵都大饭店办公楼 405 单元

Phone: +86-21-62489820

Fax: +86-21-62489821 
(C) 2012 The Author(s). Licensee IntechOpen. This is an open access article distributed under the terms of the Creative Commons Attribution 3.0 License, which permits unrestricted use, distribution, and reproduction in any medium, provided the original work is properly cited. 